\title{
"Negros, mafiosos y ortibas". Masculinidades y proxenetas en los relatos de varones que pagan por sexo en Argentina
}

\author{
"Niggers, gangsters and ortibas". Masculinities and pimps in the accounts of \\ menwho pay for sex in Argentina
}

\author{
Santiago Morcillo \\ santiagomorcillo@gmail.com \\ Consejo Nacional de Investigaciones Científicas y \\ Técnicas (CONICET) - Universidad Nacional de San \\ Juan, Argentina
}

\section{Estefanía Martynowskyj \\ estefania_mdp@hotmail.com \\ Consejo Nacional de Investigaciones Científicas y \\ Técnicas (CONICET) - Universidad Nacional de Mar \\ del Plata, Argentina}

\section{Matías de Stéfano Barbero \\ matiasdestefano@hotmail.com \\ Consejo Nacional de Investigaciones Científicas y \\ Técnicas (CONICET) - Universidad de Buenos Aires, Argentina}

Recepción: 07 Junio 2019

Aprobación: 01 Junio 2020

Publicación: 02 Agosto 2020

Cita sugerida: Morcillo, S., Martynowskyj, E. y Stéfano Barbero, M. (2020). "Negros, mafiosos y ortibas". Masculinidades y proxenetas en los relatos de varones que pagan por sexo en Argentina. Cuestiones de Sociología, 23, e102. https://doi.org/10.24215/23468904e102
Resumen: Desde principios del siglo XXI la prostitución ha vuelto a estar en el centro del debate público y feminista. Sin embargo, la investigación desde las ciencias sociales se ha ocupado relativamente poco de dos actores importantes: clientes y "terceras partes". En este contexto, algunas perspectivas construyen al mercado sexual como un espacio de sociabilidad masculina donde todos los personajes masculinos actúan como "socios". En este trabajo nos interesa indagar en la manera en que la figura del proxeneta aparece en los relatos de los varones que pagan por sexo y pone de relieve un conjunto de tensiones para su masculinidad y su sexualidad. Para ello nos basamos en dos fuentes: entrevistas en profundidad a varones que pagan por sexo y una etnografía en foros virtuales de comercio sexual. En el análisis veremos cómo la representación generizada del "fiolo" (proxeneta) que circula entre los varones que pagan por sexo se articula con el uso y los significados del dinero, de la violencia y de las emociones habilitando a repensar las relaciones entre masculinidades en el mercado sexual.

Palabras clave: Masculinidad, Sexo comercial, Clientes, Proxenetas.

Abstract: Since the beginning of the 21st century, prostitution is again at the center of public and feminist debate. However, social sciences research has focused relatively less on two important actors: clients and "third parties". Within this context, some perspectives construct the sexual market as a space of masculine sociability where all male characters act as "partners". In this paper we analyze how the representation of the pimp appears in the narratives of men who pay for sex represent the figure of the pimp and how it highlights a set of tensions for his own masculinity and sexuality. We base the analysis on two sources: in-depth interviews with men who pay for sex and an ethnography in virtual forums of sexual commerce. We argue that the gendered representation of the "fiolo" (pimp) that circulates among men who pay for sex is articulated with the use and meanings of money, violence and emotions, enabling us to rethink the relationships between masculinities in the sexual market.

Keywords: Masculinity, Comercial sex, Clients, Pimps. 


\section{INTRODUCCIÓN}

Con el resurgimiento de la "trata de mujeres con fines de explotación sexual" como problema público a principios del siglo XXI, la prostitución ha vuelto a estar en el centro del debate feminista. ${ }^{1}$ A nivel mundial se ha consolidado una perspectiva, ligada al feminismo radical abolicionista, que postula que la prostitución es una forma de violencia de género equivalente a la violación (MacKinnon, 2001 y 2011; Jeffreys, 2004). Paralelamente, desde la década de 1970, han surgido organizaciones de "trabajadoras sexuales", vinculadas casi siempre al feminismo, que luchan por el reconocimiento laboral y contra la criminalización y estigmatización, constituyendo una "amarga disputa" que sigue sin zanjarse (Lamas, 2016). ${ }^{2}$ Si bien los varones que pagan por sexo han sido un aspecto relativamente poco investigado empíricamente, desde la perspectiva del feminismo radical-abolicionista se los sitúa como sistemáticos perpetradores de violencia de género (Farley, et al., 2011; Horton y Rydstrom, 2011; Jeffreys, 2009) se considera al mercado sexual como un espacio de sociabilidad masculina que no representa problema alguno para los varones, sino que funciona más bien como (re)productor de virilidad (Chejter, 2010; Volnovich, 2006), y a todos los personajes masculinos que participan en él como "socios” (Galindo y Sánchez, 2007).

En este contexto la figura del "proxeneta", pensado frecuentemente como un varón, genera rechazo y, a la vez, una abundante producción cultural que nutre su representación. Al tiempo que es popularmente nombrado de varias formas -fiolo, 840, cafiolo, cafisho, rufián, por citar algunas de las que más circulan en Argentina-, existe una gran dificultad para brindar una definición clara de este término que permita realizar estudios comparativos así como dimensionar su presencia y rol en el comercio sexual. De hecho, la literatura sobre las denominadas "terceras partes" en el mercado sexual señala sistemáticamente la escasez de investigaciones empíricas sobre este asunto y las dificultades a la hora de plantear una definición precisa de proxeneta (Staiger, 2017; Horning y Marcus 2017, entre otros). A su vez, muy pocas organizaciones de trabajadoras sexuales han abordado este espinoso asunto. ${ }^{3}$

Todo ello lleva a que primen las definiciones jurídicas ${ }^{4}$ (muchas veces vagas) y especialmente las representaciones culturales más espectaculares y demoníacas del proxeneta. El estereotipo occidental, reproducido en el cine, la literatura, la música y algunas campañas gubernamentales, ${ }^{5}$ pareciera representar

un demonio [folk devil] construido a partir de miedos misóginos y racistas: son imaginados como hombres que viven de mujeres (invirtiendo el orden de género apropiado) y como hombres negros que controlan la sexualidad de mujeres caídas, usualmente blancas (invirtiendo el orden social) (O'Connell Davidson, 1998, p. 43).

Si bien algunas pocas investigaciones dan cuenta de formas de manejo del comercio sexual que se acercan a estos estereotipos (Montiel Torres, 2009; Smith y Christou, 2009), otros trabajos muestran realidades distintas donde, por ejemplo, suelen ser mujeres quienes operan como "terceras partes" ${ }^{6}$

El estereotipo resuena en las perspectivas radicales abolicionistas que sostienen que "el proxenetismo y la prostitución se encuentran entre las prácticas más despiadadas de poder masculino y dominio sexual" (Barry, 1995). Si la sexualidad habla el lenguaje de la dominación masculina y la prostitución es igual a "violaciones seriales" (MacKinnon, 1987), entonces los hombres que se relacionan con las mujeres en comercio sexual -cualquiera sea la posición que ocupen- sólo pueden ser "explotadores". Esta interpretación también puede leerse en el contexto latinoamericano, donde por ejemplo María Galindo y Sonia Sánchez (psicóloga feminista y activista "sobreviviente de la prostitución" respectivamente) sostienen que:

Cuando hablo de cadena de explotadores estoy hablando de una complicidad que los coloca en el mismo lugar de responsabilidad de asociación y de importancia. Son socios. Un fiolo no atenta contra el poder del prostituyente o del policía, ninguno atenta contra otro. Tampoco se colocan en una jerarquía unos respecto de los otros (Galindo y Sánchez, 2007, p. 132). 
La idea que decanta es que "proxeneta, prostituyente, policía y marido son un mismo sujeto dominador” (Galindo y Sánchez, 2007, p. 131). Otras veces esta supuesta sociedad entre clientes y proxenetas se basa en las lecturas de las posiciones estructurales de los varones "como clase", por ejemplo, tomando la propuesta de Pateman en relación a la fratria masculina y el contrato sexual (ver por ejemplo González, 2010). La idea de que las relaciones de poder entre hombres y mujeres deben comprenderse como relaciones de amoesclavo, es decir como un contrato sexual (Pateman, 1995), ha sido cuestionada por autoras. Fraser (1997), sin discutir los méritos de la teoría de Pateman para interpretar la teoría clásica del contrato social, sostiene que en el capitalismo tardío las desigualdades de género no operan mayoritariamente como relaciones de dominio y sujeción sino a través de mecanismos estructurales impersonales. En nuestro contexto, en el "contrato de prostitución" lo que se vende "es una fantasía masculina del derecho sexual masculino, fantasía que implica su precariedad en la realidad” (Fraser, 1997, p. 307). Así, la mercantilización del sexo en vez de otorgar dominio irrestricto al cliente -y ser así una ejemplificación perfecta del "derecho sexual masculino" que postula Pateman-, más bien plantea limitaciones al mismo. El contrato de matrimonio tiene una duración indeterminada donde el "marido puede obtener más fácilmente servicios fieles y un reconocimiento de su dominio" (Pateman, 1995, p. 286). En cambio, en la prostitución, generalmente fuera del marco de amor romántico, la interacción supone un enfrentamiento más claro por poner límites a la dominación e incluso disputas por los sentidos que se ponen en juego en esa performance.

Lecturas de este estilo -que parten muchas veces de reflexiones de filosofía política, más que de investigación empírica- carecen de los matices necesarios para comprender las tensiones y complejidades presentes en las relaciones de género, en el mercado sexual y en las experiencias de los varones que pagan por sexo. Como hemos observado en otros trabajos (Morcillo,et al,2020, 2018a, 2018) y como surge de otras investigaciones (Bernstein, 2001; Sanders, 2008), el comercio sexual puede presentar a los varones distintos desafíos a su masculinidad. La fantasía de "ir de putas" - sea como un escenario de dominación masculina o como un espacio festivo y descomprometido- suele entrar en tensión cuando atendemos a la narración de sus experiencias. Allí surgen "vergüenzas y riesgos que suscitan temores y abren un potencial desestabilizador de las posiciones fijas de clientes y prostitutas" (Morcillo et al., 2018).

Como veremos, la idea de que no existe una jerarquía entre los varones y que son cómplices y socios en el mercado sexual contrasta sensiblemente con las representaciones de los fiolos como figuras hipermasculinizadas, violentas y amenazantes que aparecen en los relatos de los clientes. ${ }^{7}$ Retomando la perspectiva de Raewyn Connell (2003) entendemos que las masculinidades no son identidades, esencias o formas de la personalidad, sino posiciones en las relaciones de género y poder, y por tanto diversas. Así, las posiciones que adopta la masculinidad no sólo tienen una dimensión inter-género (entre hombres y mujeres), sino también intra-género (entre hombres). Ambas dimensiones, siempre contextuales y múltiples, están atravesadas por diferentes estructuras de desigualdad como la clase o la raza, que operan interseccionalmente. Es por esto que los clientes pueden adoptar diferentes posiciones discursivas y materiales en su masculinidad de forma simultánea y, en ocasiones, contradictoria (Messerschmidt, 2018). Esto habilita a pensar cómo, aun en el mercado sexual -muchas veces descrito como un espacio de dominación masculina unívoca (varones como grupo homogéneo sobre mujeres como grupo homogéneo)- un mismo varón puede encarnar una masculinidad hegemónica en relación a las mujeres y a otros varones y, simultánea y contradictoriamente, una masculinidad subordinada frente a otros varones. A su vez, al nivel de la estructura inter-género (varonesmujeres), las masculinidades pueden tener relaciones que Connell (2003) denominó de "complicidad", donde los "dividendos patriarcales" producidos por las masculinidades hegemónicas pueden beneficiar a todos los varones -aun cuando existan simultáneamente relaciones de subordinación entre ellos-.

En este trabajo nos interesa indagar en la manera en que la representación del proxeneta aparece en los relatos de los varones que pagan por sexo, y pone de relieve un conjunto de tensiones para su propia masculinidad y sexualidad. En este sentido nos resultan fructíferos algunos elementos de la teoría de las representaciones sociales, entendidas estas como la "elaboración de un objeto social por parte de una 
comunidad" (Wagner y Elejabarrieta, 1994). Una representación, al simplificar y reducir el objeto a una figura o imagen, opera como sistema de lectura de la realidad. De esta forma, tanto las representaciones como los estereotipos -entendidos como representaciones cristalizadas (Amossy y Herschberg Pierrot, 2001) - permiten lidiar con aspectos complejos -e incluso desconocidos- de la realidad social, a la vez que estructuran valores y significados tanto sobre el objeto representado como para los grupos que sostienen su representación. Aunque no podemos ocuparnos aquí del proceso de formación ni de la estructura de las representaciones sociales sobre los proxenetas, este enfoque resulta útil en tanto permite poner el foco no tanto en las características del objeto representado sino en la relación que los grupos sociales entablan con él. Aquí nos interesa reflexionar sobre cómo la representación del fiolo-personificación simplificadora de la diversidad de entramados relacionales en el mercado sexual- permite entender la compleja relación entre masculinidades, poder y sexualidad en los clientes. En este escenario, la figura del proxeneta, que muchas veces no emerge de una experiencia de sociabilidad concreta, sino que es imaginada, aparece como un estereotipo masculino que representa una hipermasculinidad amenazante, de la que parece necesario alejarse y diferenciarse, o incluso confrontarla. En el análisis veremos cómo la representación del "fiolo" funciona como un espejo oscuro donde los clientes miran su masculinidad y su sexualidad en el marco de las relaciones de género jerárquicas entre varones. A continuación, planteamos que la imagen del fiolo aparece en las narrativas de los clientes ligada a la emoción del temor hacia la violencia. Se presenta como un "otro" que, además de generizado, está marcado por la raza y la clase. Veremos luego que esta otredad resulta amenazante para los clientes, no sólo en términos físicos, sino también para su masculinidad, expresada en su relación con el dinero, con la moralidad y con la sexualidad y las emociones. Finalmente, sugerimos que el estereotipo del "fiolo" es utilizado como una categoría de acusación que siembra sospechas sobre las fronteras entre el "nosotros" (clientes) y los otros (fiolos), al tiempo que invisibiliza otras "terceras partes" que se alejan de esos estereotipos masculinos.

\section{Metodología}

Para hacer el análisis que proponemos en este artículo, en el marco de un proyecto de investigación más amplio, ${ }^{8}$ nos basamos en dos fuentes: entrevistas en profundidad a varones que pagan o que han pagado por sexo y foros virtuales de comercio sexual. En ambos casos son varones cis heterosexuales, nos referiremos a estos varones pues son los principales protagonistas del foro. ${ }^{9}$ Por una parte, realizamos 19 entrevistas en profundidad en las ciudades argentinas de San Juan y Mar del Plata a varones que pagan por sexo. ${ }^{10}$ Accedimos a los entrevistados a través de trabajadoras sexuales (participantes en investigaciones anteriores), contactos personales y utilizando la técnica de bola de nieve. Cabe destacar que, a pesar de estas múltiples vías de acceso, dar con los entrevistados resultó difícil, lo cual, ya de desde el inicio de la investigación, brindó un dato relevante sobre la reticencia con la que circula la información sobre el sexo pago y sobre cómo la categoría de "cliente" plantea, en general, una interpelación problemática. Teniendo en cuenta estas dificultades en el acceso conformamos una muestra de conveniencia buscando la mayor variabilidad en términos de sectores socioeconómicos y edades. Los entrevistados tenían entre 27 y 77 aos, ocupan diversas posiciones socioeconómicas y sus niveles educativos varían desde primario incompleto hasta estudios universitarios completos.

Por otra parte, realizamos una etnografía virtual, es decir, utilizamos métodos etnográficos para analizar las interacciones entre los actores de la cultura o espacio de sociabilidad virtual (ver Álvarez Gandolfi, 2016). En particular nos interesa aquí seguir los enfoques de la etnografía virtual que ponen el foco en las mixturas online / offline para comprender cómo los espacios virtuales forman parte y retroalimentan los mundos culturales en nuestras sociedades (Hine, 2015). Conducimos esta etnografía en foros de internet sobre comercio sexual, que funcionan como espacios de opinión e intercambio sobre sexo comercial de acceso 
público. Los dos foros seleccionados se encuentran online desde 2004 y son los más numerosos de Argentina (al momento cuentan con 192.012 y 386.446 usuarios). Si bien cada foro tiene sus reglas, ambos comparten la gratuidad, el objetivo de intercambio de experiencias y un sistema de reputación de los usuarios (de quienes además se muestra su trayectoria de participación). En este espacio de sociabilidad virtual, algunos de los varones que pagan por sexo comparten sus experiencias ("XP") por medio de narrativas de sus encuentros con "escorts", otros piden información sobre un servicio, pero además hay varios hilos sobre "temas generales" donde dialogan sobre cuestiones que muchas veces exceden los encuentros e incluso al mercado del sexo. Para este trabajo, a fin de analizar las representaciones de estos "otros varones" ligados al comercio sexual y sus articulaciones en términos de masculinidades y sexualidades, realizamos búsquedas a partir de los términos clave fiolo, cafiolo, cafisho, proxeneta, $840^{11}$ y madama. Para cada término clave se leyeron todos los hilos relevantes de forma sistemática y se revisaron además otros hilos asociados por derivación y las secciones offtopic de temas varios, donde los usuarios suelen plantear reflexiones e interrogantes más amplios. Además, si bien no es posible lograr exhaustividad en foros donde los mensajes alcanzan varios millones y están en constante crecimiento (al momento de escribir este artículo, uno de los foros cuenta con 2.267.843 mensajes y el otro, más antiguo, contiene 6.566 .042 mensajes de usuarios), nuestra indagación sí tuvo como criterio la saturación de los sentidos de cada categoría en análisis.

\section{Riesgo y TEMOR}

Nosotros éramos pendejos y éramos re barderos. Y siempre aparecía la figura del fiolo como diciendo: "Che, no manden fruta porque acá estamos nosotros" (León, 30 años, desocupado).

En las narrativas de los clientes, el fiolo aparece recurrentemente como una de las principales figuras que pone límites dentro del mercado sexual. Robert Smith y Maria Christou (2009) señalan que, así como las prostitutas tienen que exudar un "halo de sexualidad", los fiolos tienen que exudar un "halo de violencia latente". Según lxs autorxs, la violencia sería parte de su capital, que usarían tanto para controlar a las prostitutas, así como para protegerlas de los clientes que quieran "pasarse de la raya”.

Lejos de ser un "socio" o un "cómplice" miembro de la fratría masculina, el fiolo suele considerarse como un riesgo para los clientes y aparece muchas veces vinculado a las "malas experiencias" que pueden tenerse en el mercado del sexo: "Le llamo malas experiencias a que se te queden con la plata o que aparezca un tipo y te pegue. Son cosas que pasan también” (Esteban, 67 años, jubilado). En la mayoría de los casos no suelen relatarse encuentros directos con los fiolos; sin embargo, el "halo de violencia latente" de su representación aparece igualmente, generando una emoción más frecuente de lo pensado: el temor.

Por lo que he leído, por suerte no tuve esos quilombos, pero ha habido gente que ha tenido experiencias muy malas, de trato, de tener un tipo en el baño, ¿viste? Escuchás una tos y tenés un tipo que está en el baño. Ahí te das cuenta los peligros a los que uno se somete. No solamente ellas, pobres, sino también uno. (Lucio, 30 años, empleado de comercio)

[Más que la policía] da más cagazo el fiolo que puede estar escondido en alguna parte del departamento, que te arme algún quilombo. Y se preguntarán... ¿ ¿miedo a qué?, si pactás por un servicio y lo pagás. Sí... pero siempre está el negrito avivado detrás de todo eso, que a lo mejor vos pagaste y ponele que después te quedaste no sé, 5 minutos más y la mina te diga: “iah, pero ya pasó más tiempo, me tenés que pagar más!" Esto lo estoy diciendo como algo que se me ocurre, nunca me pasó y ojalá nunca pase, pero... ¡acá nunca se sabe!(Usuario 1, hilo "Ley de De la Sota - leyes sobre prostitución”, Foro 1).

Independientemente de que las experiencias sean narradas como concretas o potenciales, los fiolos parecen condicionar las formas de consumo de los clientes. Esteban antes buscaba en la calle, pero ahora tiene los teléfonos de las “conocidas". Las lleva a su casa preferiblemente, por una cuestión de costos, o va a sus departamentos, pero aclara: "no confío yo, por si aparece un tipo. Hay mucha cosa viste... pegada. La mayoría de los departamentos, siempre están prendidos los policías, todo".

Según la investigación de Teela Sanders (2008) en Inglaterra, los clientes asocian la prostitución callejera con los pimps [fiolos] y la explotación, lo que es visto como riesgoso y a la vez como "inmoral". En el 
contexto argentino, esta caracterización suele aparecer más frecuentemente ligada a los "privados"12 y no tanto a la prostitución callejera. La idea de evitar riesgos aparece en los relatos de algunos entrevistados que representaban a los fiolos como figuras ligadas a otros negocios ilegales como el robo, la venta de drogas o simplemente relacionados con una ilegalidad indeterminada: "no sabés en qué andan metidos", señalaba Carlos. El fiolo también aparece como peligroso porque es imaginado como alguien capaz de ejercer violencia repentinamente; en palabras de Sergio: "en un ratito se te da vuelta toda la diversión". Como nos relató Daniel, la mera presencia de los fiolos y su imprevisibilidad bastaron para generarle temor:

Una vuelta fuimos a comer un asado a una finca con unos jefes, en Córdoba. Había un cordobés muy putañero, el desgraciado. Y estando ahí, comiendo, tomando, pidieron un servicio, que trajeran unas mujeres. Llamaron por teléfono. Llevaron tres esa vuelta, [nosotros] éramos cuatro o cinco. Los vagos que las trajeron se quedaron afuera. Las trajeron en un auto hecho bosta. Se bajaron las minas, todas bucaneras, bien yira las vagas. Los vagos que las trajeron nunca se fueron, se quedaron en la puerta, que estaba un poco lejos. El temor, ¿viste? Mirá si a estos boludos se les sale la chaveta y se arma una cagada ahí adentro. Esas cosas las tuve siempre... cuidándome un poco. (Daniel, 64 años, enólogo).

La representación del fiolo como alguien de aspecto extravagante y amenazador, fogoneada por los medios de comunicación y la cultura popular, también aparece en varios relatos en los foros. Un usuario de uno de los foros relató la sensación de intimidación cuando vio a una prostituta subirse "al auto de su nuevo fiolo. Este personaje tenía cara de mafioso, anteojos negros y auto sin patente" (Usuario 2, Hilo "Escorts Mañeras", Foro 2).Otro usuario escribió en el foro para advertir a sus "compañeros gateros":

Los fiolos parecen mafiosos siguiéndote por todos lados. Como en el edificio de Sarmiento, comprobando tu cara por tu número de whatsapp para ver si te vuelven a aceptar la llamada para subir o no [al departamento]. Mucho cuidado compañeros gateros. (Usuario 3, Hilo "Hablando entre nosotros", Foro 2).

En un hilo donde varios de los usuarios criticaban a una escort, acusándola de robar a un cliente ayudada por su fiolo, se planteaba:

Ya el solo hecho de ir a coger y saber que hay un negro con un chumbo espiando atrás de la cortina esperando para que le pagues, lo dice todo. No sé qué usuario del foro va a querer ir a visitarla, por manejarse así ya se quemó para toda la vida, hubiera sido más viva y tener algo de respeto por el cliente que le da de comer a ella y al negro ñoqui.(Usuario 4, Hilo "Pasandola de lujo con Yesi! linda pendeja", Foro 2).

Este relato condensa varias de las dimensiones que atraviesan las relaciones entre los clientes, las prostitutas y los fiolos. Además del temor que despierta el fiolo, la mención de la complicidad entre este y la prostituta, muestra que las relaciones de poder y de género entre los actores del mercado sexual son múltiples. ${ }^{13}$ En este caso, la complicidad entre dos para subordinar a una tercera parte no es entre fiolo y cliente, sino entre prostituta y fiolo, donde este último es el que ejercería o amenazaría con ejercer la violencia física. ${ }^{14}$

Por otra parte, este usuario alude explícitamente a la condición de "negro ñoqui" del fiolo. En Argentina, esta expresión no implica únicamente una forma de racialización, sino también de distinción de clase: a la que aludía explícitamente otro usuario al señalar el auto "hecho bosta" en el que los fiolos llegaron a una fiesta, a la que alude este usuario al referirse al fiolo como un "ñoqui" ${ }^{15}$ o usuario 1 cuando mencionaba al "negrito avivado" en un sentido similar. Ambas variables, clase y raza, pueden ser contextualmente utilizadas como forma de subordinación entre las masculinidades, pero también como formas de hipermasculinidad amenazante (Connell, 2003; Messerschmidt, 2018). Si bien desde una perspectiva interseccional podemos ver que la construcción de la imagen de los fiolos varía en diversos contextos, la racialización y el posicionamiento en clases subalternas suelen contribuir a que el fiolo se presente más como un "otro" para la masculinidad de los varones que pagan por sexo que como un cómplice de la fratria masculina.

En el próximo apartado, introduciendo la dimensión del dinero y la moralidad, veremos cómo se configura la intersección entre clase y sexualidad en el juego de posiciones intra-género entre fiolos y clientes. 


\title{
4. Dinero, MORALIDAD Y MASCULINIDAD
}

\begin{abstract}
Mi forma de construir es destruir a los fiolos (pero no a las minas, con las que suelo ser hasta generoso). Si todos destruyéramos a los fiolos, las escorts serían independientes, los precios serían distintos y la sensación de estafa que te queda después de visitar un privado no existiría. (Usuario 5, Hilo "Mejor dato", Foro 2).

Algo cierto también es que estos culiados aumentan el precio de los servicios, debido a que hay más gente para repartir lo producido de las chicas, pero siempre me pregunté por qué ciertas minas que son inteligentes y están muy buenas, que podrían laburar solas, están a merced de estos tipos y bajo su ala (Usuario 6, Hilo "Me siento mal, odio a los 840", Foro 2).

Una cosa es contratar trolas y otra es darle de comer a los hijos de puta. A estos hijos de puta tendrían que darle el mismo trato que a los violetas [violadores]... (Usuario 7, Hilo "Cuidado", Foro 2).
\end{abstract}

Hemos visto que algunas de las amenazas que los fiolos representan para los clientes están relacionadas a las posibilidades de sufrir agresiones y/o robos. Otras también involucran la dimensión económica, como en los ejemplos citados arriba que muestran la preocupación de los "gateros" por los fiolos como agentes que "encarecen" el servicio. Sin embargo, el profundo descontento que expresan estos usuarios revela que esta preocupación no se limita a la dimensión monetaria. Como sostiene Viviana Zelizer, el dinero no es neutral, impersonal ni fungible, sino que "circula como una moneda cargada de sentido, profundamente subjetiva y no fungible, fuertemente regulada por convenciones sociales" (2008, p. 5).

Uno de los significados que asume el dinero tiene que ver con las normas de género que estructuran sus formas de circulación. Aquí nos importan especialmente las relaciones que se tejen entre dinero y masculinidad. Smith y Christou (2009) señalan que el rol de los fiolos iría en contra de la idea de "ser hombre", porque sacar réditos económicos del trabajo de las mujeres o "vivir de ellas" sería vergonzoso para un hombre y cuestionaría la posición de la masculinidad dominante. ${ }^{16}$ Ser un fiolo trastocaría el orden de género "apropiado" que ubica a los varones como proveedores, por ello Julia O 'Connell Davidson (1998, p. 43) lo plantea como una inversión del orden de género.

A su vez, si pagar por un servicio sexual es considerado un uso legítimo de dinero por estos varones, cuando el dinero se "desvía" a un fiolo se altera el patrón de intercambios sexo-económicos (dinero por sexo). Aparece entonces la preocupación por que dicha alteración (dinero por explotación) introduzca (otras) formas de subordinación intra e inter-género. En el primer caso emerge la inquietante posibilidad de quedar subordinado a otro varón.

Yo no siento nada por las prostitutas, ni amor ni odio, sólo las quiero para culiar un rato, pero los 840 si me caen bastante mal. Y decir eso de "es lo que hay, no hay nada que hacerle" en lugar de idear un modo de meterle la pija a ellos es como dejarlos ganar a esos tipos, que son los tipos que están entre las escorts y yo. Si el fiolo no existiera, me bancaría estoicamente toda la mierda de la prostitución local, pero desde el momento en que la guita que le doy a una mina es fraccionada para alimentar a uno de estos vividores, entonces me siento obligado a dar la pelea (Usuario 5, Hilo "Cooperativa Gatera", Foro 2).

Varios usuarios coinciden con este relato de que hay que "dar pelea" frente a las relaciones de subordinación que imponen los fiolos a nivel intra-género. La jerarquización entre masculinidades no supone que exista una masculinidad hegemónica (podríamos pensar, en este caso, la de los fiolos), y una masculinidad subordinada (la de los clientes). Como ya hemos apuntado, las masculinidades son posiciones en las relaciones de género, no se trata de identidades, esencias, o rasgos de la personalidad. Siguiendo las propuestas de Connell (2003) y Messerschmidt (2018), la posición hegemónica de la masculinidad es aquella que legitima en su discurso y en su práctica una relación jerárquica entre hombres y mujeres, entre la masculinidad y la femineidad y entre las propias masculinidades. Es por ello que las masculinidades de los fiolos y de los clientes pueden situarse simultáneamente en diferentes posiciones en cada una de las formas de relación en las que se ven involucrados. Incluso las formas de resistencia a la subordinación intra-género pueden reproducir las formas de hegemonía y jerarquización del género. Cuando "Usuario 5 " se siente amenazado por los fiolos y señala que hay que "idear un modo de meterles la pija”, se sitúa simultáneamente en una posición de subordinación intragénero pero reproduce la masculinidad hegemónica al considerar una jerarquización entre masculinidades 
(fiolo-cliente) y, al sugerir como forma de resistencia la subordinación de los fiolos a través de la penetración, reproduce la jerarquización entre masculinidades a través de la homofobia. Como señalan Connell (2003) y Messerschmidt (2018), la heteronormatividad de la masculinidad hegemónica hace que la homofobia sea una de las formas de subordinación entre masculinidades, pero la homofobia está atravesada también por un componente de género. Si consideramos la dicotomía femenino/pasivo y masculino/activo, la penetración del otro como forma de subordinación -a la que alude también otro usuario cuando señala que habría que darles el mismo tratamiento que a los violadores en los contextos de encierro, es decir, violarlos-, no sólo implica una jerarquización intra-género -subordinar a la masculinidad de los fiolos- sino también una jerarquía inter-género, ya que se considera lo pasivo como femenino y lo activo como masculino. De esta manera, una forma de confrontación implica dos formas simultáneas de reproducción de la masculinidad hegemónica.

La multiplicidad y simultaneidad de posiciones también puede observarse cuando otro cliente señala en un foro:

En esto, nosotros, los que consumimos este tipo de sexo, debemos denunciar estos casos. Es la manera de ayudar a desarmar a estas bandas de hijos de puta. La libertad de usar el cuerpo propio como uno quiera es lo que debe imperar y no que se haga a la fuerza. Vamos a ver como les va cuando estén en [la cárcel de] Devoto con los muchachos ansiosos de carne fresca. Abrazo (Usuario 9, Hilo "Cuidado", Foro 2).

En este relato, el cliente valora la independencia y la libertad de usar el propio cuerpo de las prostitutas y rechaza la subordinación que les impondrían los fiolos. Sin embargo, su propuesta es denunciar y encarcelar, suponiendo que el destino de los fiolos en las cárceles es, nuevamente, el de ser violados por otros internos, lo que nuevamente reproduce una jerarquización entre masculinidades.

Por otra parte, las relaciones de subordinación en el mercado sexual tienen también un componente intergénero que inquieta a varios de estos varones. La preocupación por el aumento de costos cuando "hay más personas para repartir" a la que aludimos más arriba vehiculiza también, en ocasiones, una preocupación por la explotación en el mercado sexual. La objeción moral que se evidencia (por ejemplo, cuando se cuestiona: "siempre me pregunté por qué ciertas minas que son inteligentes y están muy buenas, que podrían laburar solas, están a merced de estos tipos"), sirve para diferenciar "su comportamiento como aceptable en comparación con el de otros hombres que explotan a mujeres" (Sanders, 2008, p. 51). El rechazo al fiolo incluye la idea de que "lucran con ellas", posición que permite reconfigurar la masculinidad de los clientes restableciendo su "respetabilidad" (Skeggs en Sanders, 2008). Un usuario del foro, advirtiendo sobre los privados, donde suponen que hay mayor explotación, señalaba:

Es de alguna forma protegerlas de vivos que lucran a costa de ellas. (...) ya que somos gateros empecemos por cuidarlas. (Usuario 10, Hilo “Cuidado con estos lugares!", Foro 1).

Y en otro hilo similar agregaba:

Igual no te hagas problema que si denunciamos varios a ese lugar o a otros donde haya fiolos maltratando a las chicas, por
mi parte denunciaré. En algún momento algo pasará. Y a todas las minas que nos leen, dejen de ser carne de cañón de estos
giles que les hacen creer que están protegidas. Es mentira, al contrario, ellos son los peores, peores que cualquier loquito que
se les pueda cruzar como cliente, que a esos se les puede evitar más fácil que un fiolo. Conozco cómo se manejan los fiolos
y no hay ni uno bueno. Para ellos las minas no son nada solo la entrada de plata que les dan fácil. (Usuario 10, Hilo "Duda
con dpto.", Foro 1).

La figura del "varón protector" (Messerschmidt, 2018) aparece contrapuesta a aquella de los fiolos, para quienes las prostitutas "no son nada, sólo la entrada de plata". Lucio, uno de nuestros entrevistados ya mencionado, que en general ha consumido en contextos grupales, decía lo siguiente:

Yo creo que el 95\% de los clientes no quiere ni saber qué pasa atrás, porque el que sabe y tiene buen corazón, no quiere saber más nada. Y al otro no le importa, porque no le importa. "No che, a esta la tienen acá y después viene el flaco y la caga a palos", impresentable. Si yo se eso, y sé quién es el flaco, es para romperlo todo, es un hijo de puta. 
Esto desafía el supuesto de que el consumo de prostitución es aproblemático para los varones, pues, como se ha señalado en otros estudios, muchos "expresan repulsión ante la idea de comprar sexo a mujeres vulnerables o coaccionadas" (Sanders, 2008, p. 55). En las expresiones de los clientes conviven la indignación moral frente a la explotación de las mujeres con la revalorización de su posición masculina como protectores/salvadores que buscarían ajusticiar (violentamente) a los fiolos explotadores.

Estas expresiones de rechazo constituyen al mismo tiempo un "nosotros" de "cofrades gateros". En el siguiente discurso, en un hilo significativamente titulado "Me siento mal, odio a los 840 ", un usuario manifiesta su profundo rechazo a los fiolos:

Me estuvo pasando que es como si sintiera un odio intrínseco a esos malditos tres números (840) (...) Será que el punto donde concentro mi ira es sentir que le doy de comer un h.d.p. de esos quienes carajillo sean (...) si fueran menos ortibas ${ }^{17}$...si dejaran al sexo en plena democracia...al menos no lo sé...habría más libertad lejos de sus presiones de: "ya es la hora... ¿estás bien?, dale, te espero en tal lugar". Es justamente allí cuando siento por dentro adoptar sentimientos malos hacia ellos, pues soy sincero, los odio! A mis amigos los cofrades que entienden lo que digo, muchas gracias por leerme, me siento contenido por ustedes, porque sé que al menos algunos de ustedes sienten lo mismo que yo. (Usuario 11, Hilo "Me Siento mal,odio a los 840 ”, Foro 1)

La enunciación de esta comunidad homosocial (los gateros) en el rechazo a la figura del fiolo no solo produce un otro contra quien construir identidad, sino que deja entrever la fragilidad de la fantasía relacional que entablan. Este usuario no sólo "odia" a los fiolos porque siente que "les da de comer", sino especialmente porque con sus intervenciones -o "presiones"- rompen la "democracia" del sexo entre clientes y prostitutas e introducen elementos disruptivos para esa fantasía horizontal y deseante, tal como veremos en el siguiente apartado.

\section{LA RUPTURA DE LA FANTASÍA}

Es horrible ir a un prostíbulo (...) a mí me parece que los jóvenes (...) ni en pedo iríamos a una onda prostíbulo... uno se acostumbra a tratar directo con las chicas como si fueran una mina que conoces en cualquier lado. (Usuario 1, Hilo "Ley de De la Sota - leyes sobre prostitución”, Foro 1).

Los más jóvenes todavía queremos "cazar", por eso una buena mina independiente, que no se pasa todo el día garchando en un depto, es como una joya. Es casi como garchar "engañados" con una mina del barrio que te levantaste. La mina que es joven y garcha porque le gusta y de paso hace unos mangos es un tesoro y hay pocas de esas. Supongo que esa es la motivación de la mayoría por las independientes (más allá del tema de trata de personas). Estimo que, cuando uno esté entrado en años, no tendrá ganas de seguir renegando y buscará algo parecido a una onda prostíbulo regenteado por una madame, donde pase un buen momento sin mucho preámbulo. (Usuario 12, Hilo “Ley de De la Sota - leyes sobre prostitución”, Foro 1).

Para algunos varones la intervención de fiolos o terceras partes en los encuentros entre clientes y prostitutas desarma la fantasía de conquistar ("cazar") y del deseo mutuo que permite disfrazar el aspecto comercial del encuentro y alimenta el (auto) engaño de los gateros. Esto sucede especialmente entre los más jóvenes, quienes se supone cuentan con mayor capital erótico ${ }^{18}$ y conocen menos el funcionamiento del mercado sexual y por tanto pueden (¿y necesitan?) sostener ese carácter fantaseado de la relación.

El recelo hacia la intervención de fiolos o terceras partes en las relaciones con las escorts también se hace evidente si consideramos que uno de los puntos que los gateros siempre valoran en sus narrativas de encuentros (las llamadas "XP") es si la escort es independiente o no. La idea de la "escort independiente" funciona como un potenciador de la fantasía de estar con una mujer cuyo deseo sexual excede al promedio: la "puta lujuriosa".

O sea, sin fiolos, esas minas serían independientes, y las culiaríamos y, al menos yo, me bancaría todo lo que pueda pasar, porque es un asunto entre ella y yo. Pero desde que hay un fiolo metido en el medio, desde que te golpean la puerta, o te dejan esperando para entrar, o te hacen cagarte de calor en un departamento choto o cosas así, entonces tengo derecho al mejor servicio y al mejor precio. (Usuario 5, Hilo “Mejor dato", Foro 2). 
No sólo la imagen del fiolo como otro varón que media en la relación cliente-escort, sino también algunas de sus funciones hacen explícito su rol disruptivo en la fantasía gatera. Muchas veces los fiolos son los encargados de avisar que el tiempo del encuentro ha concluido. Esta función hace que aparezcan como una irrupción en la fantasía de conquista, intimidad y deseo mutuo. Retomando las ideas deleuzianas sobre el tiempo (Brewis y Linstead, 1998), podríamos decir que los 840 quiebran el tiempo "fluido" que construye el encuentro en tanto que fantasía, e imponen la realidad del tiempo "estriado", delimitado y ligado a la tarifa. Aquí se mezclan los motivos económicos con los emocionales, pues cuando el fiolo golpea la puerta significa a la vez que el tiempo pagado por el dinero ha concluido, su valor se ha agotado, queda expuesto el carácter lucrativo del encuentro y, a la vez, aparece en escena un otro varón que, en las narrativas de los "gateros", tendría el control de esa sexualidad que ellos desean y por tanto la fantasía del deseo mutuo queda amenazada.

Esta fantasía, que pretende velar las posiciones jerarquizadas prostituta-cliente, se derrumba ante las disrupciones que introduce la presencia de los fiolos. Queda expuesto el carácter precario y endeble de esa fantasía -y también la fragilidad de esta articulación entre masculinidad y sexualidad- y el escenario del comercio sexual parece más sujeto a la falla en este sentido (por ejemplo, si contrastamos con las relaciones románticas donde todo el ideario del amor desinteresado funciona mucho más efectivamente como forma de mantener la ilusión).

Asimismo, al resquebrajar la fantasía, el papel del fiolo es también relatado como una amenaza de violencia para quienes sobrepasan los límites y no mantienen un control de sus emociones, es decir para aquellos clientes que se enamoran.

Los códigos son que uno no se tiene que enamorar y que ellas tampoco, porque además es muy peligroso, porque siempre hay alguien que te va a correr del medio, o el cafiolo, o el marido, o la familia. Hay mucha gente, muchas chicas que trabajaban con el marido, con su pareja, entonces te van a correr, te van a cagar a trompadas, eso funcionaba así, no sé cómo será ahora. (Nicolás, 45 años, comerciante).

El fiolo como varón que maneja y controla la sexualidad de la prostituta aparece entonces como una figura amenazante y que preocupa a los clientes, pues no sólo puede imponer el límite de la fantasía deseante que construye un vínculo prostituta-cliente sino que además lo hace desde un lugar de poder y con capacidad de violencia.

Sin embargo, el límite que transgreden aquellos clientes que se enamoran también es vigilado y sancionado por algunos gateros. Quienes se enamoran de las escorts y/o las "defienden" son frecuentemente acusados de 840 , a veces porque "inflan el servicio" de una escort, otras veces porque "pagan de más".

Hay que tomar en cuenta que hay mucho gatero enamorado y mucho gatero (ocho) cuarentón que se pasan de generosos.

(Usuario 5, Hilo "Gatopedia”, Foro 2).

En este hilo el Usuario 5 se preocupaba por cómo el enamoramiento de algunos gateros podía trastocar la "objetividad" de su evaluación sobre el servicio de las escorts (y por ende poner en riesgo su proyecto de armar un ranking de escorts: "Gatopedia"). Tanto los enamoramientos como otras sospechas generan dudas sobre la identidad de los otros en el foro, que serán muchas veces expresadas, como veremos a continuación, a través de la acusación de fiolo entre los propios usuarios.

\section{ENTONCES... ¿QUIÉN ES EL "FIOLO"?}

Por fin un colega que está con los pies sobre la tierra relatando la realidad de lo que está pasando (...) Estaba harto de leer las experiencias de los fiolos disfrazados de colegas que decían que no tenían problema en gastar 2 lucas o 3 lucas en putas. Lo felicito colega lo que usted dice es la realidad (Usuario 13, Hilo "Morocha Noe y Pampita, trio en Tijuana”, Foro 2).

Un punto clave y recurrente es que, aun cuando la cantidad de narrativas sobre encuentros reales con fiolos no es tan grande, la categoría de 840 o fiolo funciona como una sospecha constante sobre alguien que 
interviene en el debate en el foro, especialmente para quienes no tienen una "trayectoria" comprobada y por ende la legitimación de los otros gateros. Buena parte de las intervenciones de los usuarios apuntan a descubrir quién es un fiolo participando de encubierto en el foro. Esta sospecha engendra un neologismo: los "clonegas", conjunción entre "colega" (aquellos gateros de confianza o "gateros de ley") y un "clon", es decir, un usuario falso que ha sido "clonado" por otra persona. El enfrentamiento con los 840 lleva a varias iniciativas para combatirlos y desenmascararlos:

La propuesta es muy sencilla. No publicar más en PÁGINAS de 840. Publicar en blogs y ahorrarse el dinero de la publicación. En https://www.blogger.com pueden hacer chicas su propio blog, es gratuito y muy sencillo. Seguro los gateros de ley y no los 840 disfrazados de gateros apoyaran mi propuesta, la cual beneficia a las escorts porque se ahorran el dinero de la publicación y beneficia al gatero de ley porque los precios serán más baratos, porque ya no serán impuestos por los 840 . A continuación, veremos si en este foro hay gateros de ley que apoyen mi propuesta o un montón de 840 camullados que no la apoyan. Ustedes observen y saquen sus conclusiones. (Usuario 14, Hilo "Propuesta para erradicar la trata, los 840 y beneficiar a las escorts", Foro 2).

Aquí podemos ver que la necesidad de sostener el anonimato en los foros -como forma de protección frente al estigma, y/o de sostener acuerdos matrimoniales pretendidamente monogámicos- puede ser también percibida como un factor que incrementa el riesgo siempre presente de ser engañados (pasando de engañadores a engañados), especialmente de ser engañados por una mujer en complicidad con otro varón.

En el foro 840 o fiolo funciona como una categoría de acusación que puede caer sobre cualquier usuario como forma de desacreditarlo, la mayor parte de las veces sin argumentar motivos. Thaddeus Blanchette y Ana Paula Da Silva (2017) plantean, para el caso del mercado sexual en Brasil, un uso más o menos estratégico de la categoría que sería equivalente a fiolo: el cafetão ${ }^{19}$ es muchas veces usado para movilizar recursos policiales/ judiciales contra algún actor: ${ }^{20}$ "Cafetão o cafetinha son universalmente considerados como negativos y son usados por trabajadoras sexuales, policías, medios de comunicación y miembros de la sociedad civil, como una acusación" (Blanchette y Da Silva, 2017, p. 25).

Un aspecto importante de cómo funciona esta acusación son las especificidades que esta tiene para cada actor del mercado sexual. En nuestro caso, encontramos que la acusación de fiolo se halla generizada entre los clientes. Ello tiene incluso una expresión en el lenguaje. Mientras Blanchette y Da Silva indican que en portugués también existe otra palabra para designar exclusivamente a varones ("gigolo"), en Argentina sucede a la inversa y será madama la categoría que designa exclusivamente a mujeres. Ello nos permite poner de relieve cómo, cuando 840 o fiolo es utilizado como una acusación entre los clientes que participan del foro, esta alude casi siempre a varones.

Si 840 es una categoría muy común en la jerga de los gateros (tanto que uno de los foros lo catalogaba como un término demasiado común para una búsqueda), el equivalente feminizado, madama, es pocas veces mencionado. Una de las pocas menciones que encontramos construía una imagen favorable de este personaje, ligado a las "viejas épocas" del cabaret, incluso llegaba a proponer a la comunidad gatera un rescate de la importancia del rol de la madama. Las llamaba "gordas queridas" y explicaba que "dan felicidad a sus clientes con buena logística": se encargan de resolver un conjunto de tareas (ligadas a la domesticidad y generalmente feminizadas) que hacen que el gatero se sienta atendido "como un rey" en su "segundo hogar" (atender el teléfono para que no haya interrupciones, mantener la limpieza de sábanas y baños, entretener con charla y servir un vaso de agua al gatero mientras espera).

Esta defensa de la madama sería impensada en el caso de un fiolo. Ello permite entender que, en articulación con el papel económico del fiolo como alguien que "malversa" los dineros de los gateros, hay una tensión generizada. El fiolo, en tanto es otro varón -y, siguiendo la representación de los clientes y la imaginería popular, un varón hipermasculinizado- resulta una amenaza para los gateros, pues pone en riesgo dos elementos muy ligados: los recursos económicos y la virilidad. 


\section{REFLEXiOnes FinAleS}

A lo largo de este trabajo hemos podido observar las representaciones de los fiolos en las narrativas de los varones que pagan por sexo y la complejidad que adquieren sus posiciones en las relaciones de género. Como hemos sealado, algunas perspectivas sobre el mercado sexual presentan las relaciones de género de manera rígida, determinista y reduccionista, limitando las relaciones inter-género a relaciones de dominación y considerando las relaciones intra-género (entre varones) como aproblemáticas y únicamente basadas en la complicidad. Estas miradas suponen que la prostitución es un escenario que reproduce una dominación lineal de varones hacia mujeres, donde los proxenetas sostienen el pacto patriarcal entregando "sus mujeres" a quienes pagan por ellas.

Desde los estudios de masculinidades y desde una perspectiva de las relaciones inter e intra-género, se hace difícil pensar en los varones como "clase" homogénea y por ello en fiolos y clientes como "socios" que se relacionan sin intermediación del poder o de formas de jerarquía. Si bien, al menos en nuestro trabajo de campo, buena parte de las relaciones entre clientes y fiolos tienen un carácter mayoritariamente imaginado, la aparición constante de su representación en las narrativas de los varones que pagan por sexo afecta sensiblemente sus experiencias en el mercado sexual. La vinculación con los proxenetas se muestra como conflictiva para los clientes, que ven en ellos figuras que generan temor y amenazan su masculinidad, tanto a nivel material como simbólico, y es por ello que, lejos de convivir, prefieren evitarlos y/o confrontarlos. La presencia de los fiolos supone una pérdida a nivel económico - un aumento de las tarifas- un dilema moral -vinculado a la explotación que estos hacen de las "prostitutas"- y una afrenta a la masculinidad de los clientes en tanto que proveedores.

Como hemos visto en los discursos de los clientes, las representaciones de los fiolos están atravesadas por relaciones económicas, de clase, raza, edad y también emocionales. La circulación de un estereotipo del fiolo como hipermasculino y violento, racializado y de clases subalternas lo pone en un lugar distante y amenazador. Pero también las propias relaciones entre los clientes encuentran en el fantasma omnipresente del fiolo una forma de construcción de un "nosotros" (gateros) frente a un "otro" (fiolo). Los "gateros" utilizan fiolo como una categoría de acusación que delimita las fronteras de su pertenencia al "nosotros" pero, al mismo tiempo, extiende una sospecha constante sobre ellos mismos, poniendo en tensión la propia cofradía de "gateros". Simultáneamente, la hipermasculinización de la representación del fiolo que circula en las narrativas de los clientes invisibiliza el papel de las mujeres como terceras partes.

Las relaciones entre las representaciones de los fiolos y los clientes no sólo muestran la pugna constante por ocupar el lugar dominante en la jerarquía de masculinidades, sino que afectan también a las relaciones de género entre "prostitutas" y clientes. En ellas, el fiolo está lejos de ser el “proveedor de mujeres" en el marco de un "pacto masculino", sino que muchas veces rompe la fantasía de conquista y deseo mutuo desestabilizando la pretendida libre relación entre las partes. La imagen del fiolo, a la vez que parece manejar los aspectos económicos, actúa como regulador de las emociones de aquellos clientes que rompen el marco de interacción (por ejemplo, al enamorarse).

Todo este conjunto de tensiones pone de relieve que las relaciones entre los actores en el mercado sexual están cargadas de antagonismos y complejidades que difícilmente pueden comprenderse homogeneizando las posiciones masculinas a través de la idea del "pacto de varones". La diversidad de formas de relación inter e intra-género en el mercado sexual hace necesaria más investigación empírica, especialmente desde el campo de los estudios de masculinidades y sexualidades. Esto haría posible construir perspectivas que den cuenta de los matices en las asimetrías y las fuerzas contrapuestas que se ponen en juego en el mercado sexual, para así comprender más cabalmente los sentidos sobre género y sexualidad que allí se gestan y de qué formas estos pueden producir inequidades. Consideramos que desarrollar este tipo de enfoques, no sólo apunta a áreas de vacancia en los estudios sobre masculinidades y sobre mercados sexuales, sino que habilita a pensar modos de 
intervención que, a partir de una compresión de la complejidad del campo, resulten más efectivos a la hora de desarticular las asimetrías en las relaciones de género y las sexualidades.

\section{ReFERENCIAS}

Álvarez Gandolfi, F. (2016). Problemáticas en torno de las ciberculturas. Una reflexión sobre las posibilidades y los límites de la etnografía virtual. Cultura, lenguaje y representación, 16, 7-20. DOI: https://10.6035/CLR

Amossy, R. y Herschberg Pierrot, A. (2001). Estereotipos y clichés. Buenos Aires: Eudeba.

Barry, K. (1995). Pimping: The World's Oldest Profession. On The Issues Magazine. Recuperado de https://www.on theissuesmagazine.com/1995summer/pimping.php

Bernstein, E. (2001). The meaning of purchase. Desire, demand and the commerce of sex. Ethnography, 2(3). https: //doi.org/10.1177/14661380122230975

Bernstein, E. (2010). Militarized Humanitarianism Meets Carceral Feminism: The Politics of Sex, Rights, and Freedom in Contemporary Antitrafficking Campaigns. En Signs, 36(1), 45-71.

Blanchette, T. \& da Silva, A.P. (2017). Sympathy for the Devil: Pimps, Agents, and Third Parties Involved in the Sale of Sex in Rio de Janeiro. En A.Horning \&A.Marcus (eds.),Third Party Sex Work and Pimps in the Age of Antitrafficking (pp.15-48). New York: Springer.

Brewis, J. \& Linstead, S. (1998). Time After Time. The Temporal Organization of Red-Collar Work. Time \& Society, 7(2-3). https://doi.org/10.1177/0961463X98007002004

Connell, R. (2003).Masculinidades. México: PUEG-UNAM.

Chejter, S. (2010). Lugar común: la prostitución. Buenos Aires: Eudeba.

Davis, H. (2013). Defining 'Pimp': Working Towards a Definition in Social Research. Sociological Research Online, 18(1). https://doi.org/10.5153/sro.2826

Farley, M., MacLeod, J., Anderson, L., y Golding, J. M. (2011). Attitudes and social characteristics of men who buy sex in Scotland. Psychol. Trauma Theory Res. Pract. Policy Psychological Trauma: Theory, Research, Practice, and Policy, 3(4), 369-383.

Fraser, N. (1997). Iustitia Interrupta. Reflexiones criticas desde la posición "postsocialista". Santa Fe de Bogotá: Siglo del Hombre Editores, Universidad de los Andes.

Galindo, M. y Sánchez, S. (2007). Ninguna mujer nace para puta. Buenos Aires: Lavaca Editora.

González, M. (2010). Imaginarios y lógicas de la prostitución. Topia. Recuperado de https://www.topia.com.ar/artic ulos/imaginarios-y-1\%C3\%B3gicas-prostituci\%C3\%B3n

Green, A. (2013). Erotic capital and the power of desirability: Why 'honey money' is a bad collective strategy for remedying gender inequality. Sexualities, 16(1-2). https://doi.org/10.1177/1363460712471109

Guy, D. J. (1994). El sexo peligroso. La prostitución legal en Buenos Aires 1875-1995. Buenos Aires: Editorial Sudamericana.

Hine, C.(2015). Ethnography for the Internet: Embedded, Embodied and Everyday. London: Bloomsbury Academic.

Horning, A. y Marcus, A. (eds.) (2017). Third Party Sex Work and Pimps in the Age of Anti-trafficking. New York: Springer.

Horton, P. \& Rydstrom, H. (2011). Heterosexual Masculinity in Contemporary Vietnam: Privileges, Pleasures, and Protests. Men and Masculinities, 14(5), 542-564. doi: https://10.1177/1097184x11409362

Jeffreys, S. (2004). Prostitution as a harmful cultural practice. In R. S. Whisnant, Christine (Ed.), Not for Sale: Feminists Resisting Prostitution and Pornography (pp. 386-399). North Melbourne, Vic: Spinifex Press.

Jeffreys, S. (2009). The industrial vagina: the political economy of the global sex trade. London; New York: Routledge.

Lamas, M. (2016). “Feminismo y prostitución: la persistencia de una amarga disputa”. Debate Feminista N51, 18-35.

MacKinnon, C. (1987). Sexuality. En C.Mackinnon, Toward A Feminist Theory of the State (pp. 127-154). USA: Harvard University Press. 
MacKinnon, C. (2001). Sex equality. New York: Foundation Press.

MacKinnon, C.(2011). Trata, Prostitución y Desigualdad. Ponencia presentada en Encuentro Internacional sobre Violencia de Género, Buenos Aires.

Martynowskyj, E. (2017). Género, sexualidades, delito y moral en pantalla. Una aproximación al régimen de representación de la "trata de mujeres con fines de explotación sexual" en el cine argentino contemporáneo. KULA. Antropólogos del Atlántico Sur. Revista de Antropología y Ciencias Sociales, 17, 25-37.

Messerschmidt, J. (2018). Hegemonic masculinity: Formulation, Reformulation and Amplification. New York: Rowman \& Littlefield.

Mathieu, L. (2001). An unlikely mobilization: the occupation of Saint-Nizier church by the prostitutes of Lyon. Revue française de sociologie, 42, 107-131.

Montiel Torres, O. (2009). Trata de personas: padrotes, iniciación y modus operandi. México: Instituto Nacional de las Mujeres.

Morcillo, S. (2014). 'Como un trabajo'. Tensiones entre sentidos de lo laboral y la sexualidad en mujeres que hacen sexo comercial en Argentina. Sexualidad, Saludy Sociedad (Rio de Janeiro), 18, 12-40.

Morcillo, S., Martynoswkyj, E.y De Stéfano Barbero, M. (2020). Aprendiendo a "gatear": masculinidades y carreras morales en varones que pagan por sexo en Argentina. Aposta, 86, 67-85.

Morcillo, S., Martynoswkyj, E. y De Stéfano Barbero, M.(2018). ¿El macho “apichonado”? Masculinidad, emociones y relaciones de género en los relatos de varones que pagan por sexo en Argentina (mimeo).

Morcillo, S., Martynoswkyj, E. y De Stéfano Barbero, M. (2018).Una aproximación a los discursos sobre feminismo en varones que pagan por sexo en Argentina. Sapiens Research, 8(2), 54-62.

O 'Connell Davidson, J. (1998). Prostitution, power and freedom. Cambridge:Polity Press.

Pateman, C. (1995 [1988]). El contrato sexual. Barcelona: Anthropos.

Sanders, T. (2008). Paying for pleasure men who buy sex. UK: Willan.

Smith, R. \& Christou, M. (2009). Extracting Value from Their Environment: Some Observations on Pimping and Prostitution as Entrepreneurship. Journal of Small Business and Entrepreneurship, 22(1). https://doi.org/10.10 80/08276331.2009.10593443

Staiger, A. (2017). Perceptions About Pimps in an Upscale Mega Brothel in Germany. En A. Horning \& A. Marcus (eds.),Third Party Sex Work and Pimps in the Age of Anti-trafficking (pp.151-176). New York: Springer.

Varela, C. (2013). De la "letra de la ley" a la labor interpretante: la "vulnerabilidad" femenina en los procesos de judicialización de la ley de trata de personas (2008-2011). Cadernos Pagu, 41. http://dx.doi.org/10.1590/S01 04-83332013000200015.

Varela, C. (2016). Entre el mercado y el sistema punitivo. Trayectorias, proyectos de movilidad social y criminalización de mujeres en el contexto de la campaña anti-trata. Zona Franca, 24, 7-37.

Volnovich, J. C. (2006). Ir de putas: reflexiones acerca de los clientes de la prostitución. Buenos Aires: Topía Editorial.

Volnovich, J. C. (2018). Puteros en el diván. Recuperado de https://geoviolenciasexual.com/puteros-en-el-divan/ [22 de marzo de 2019].

Wagner, W.y Elejabarrieta, F. (1994). Representaciones sociales. En J.F. Morales (comp.), Psicología Social (pp. 1-16). Madrid: Mc Graw Hill.

Weitzer, R. (2007). The Social Construction of Sex Trafficking: Ideology and Institutionalization of a Moral Crusade. Politics Society, 35, 447-475.

Williamson, C. \& Cluse-Tolar, T. (2002). Pimp-Controlled Prostitution: Still and Integral Part of Street Life. Violence Against Women8 (9). https://doi.org/10.1177/107780102401101746

Zelizer, V. A. (2008). Pagos y lazos sociales. Crítica en desarrollo, 2, $43-63$. 


\section{Notas}

1 Si la "prostitución" estuvo presente en la agenda pública argentina durante todo el siglo XX, no pasó lo mismo con "la trata de blancas" que, luego de la sanción de la Ley de Profilaxis de las Enfermedades venéreas en 1936, fue perdiendo relevancia pública y se apaciguó (Guy, 1994). De modo que, trece años después, la "Convención para la represión de la trata de personas y la explotación de la prostitución ajena”, firmada en 1949, constituyó el último acuerdo internacional suscripto en el siglo XX respecto de la problemática de la "trata de mujeres para su comercio sexual".

Con el cambio de milenio, en un contexto de migraciones transnacionales crecientes, signado por la preocupación de los países centrales por controlar sus fronteras, el debate sobre la "prostitución” y la "trata de mujeres" reingresó al escenario transnacional a través de la sanción del Protocolo de Palermo en 2001, en Viena. Algunas autoras plantean que la renovada campaña anti-trata rearticula alianzas entre feministas y la derecha religiosa (Bernstein, 2010) o le atribuyen el carácter de "cruzada moral" (Weitzer, 2007).

2 En relación al debate feminista sobre la prostitución, desde ya es impensable una neutralidad aséptica, pero creemos que la versión dicotómica que genera la polarización de posiciones (trabajo vs. violencia) obstaculiza una comprensión más acabada de las complejidades que atraviesan al comercio sexual. Por ello, aunque somos críticxs de la estigmatización y la persecución policíaca y judicial que sufren quienes venden sexo, pensamos que situarnos meramente como "regulacionistas" no haría justicia a nuestro posicionamiento. En todo caso para ahondar en el debate, además de la bibliografía citada, podemos referir un artículo anterior donde hemos reflexionado sobre las posiciones del debate feminista y el uso de la categoría "trabajo" entre las mujeres que hacen sexo comercial (ver Morcillo, 2014).

3 La organización de trabajadoras sexuales "Stella" en Canadá, en la versión en español de la guía "Dear John” orientada a los clientes, señala que las trabajadoras sexuales optan por distintas formas de ejercer su trabajo (independientes, entre colegas o con propietarios de agencias) y agrega: "La imagen estereotipada del pimp es la de un hombre que controla el trabajo y el dinero de una mujer que ejerce el trabajo del sexo (...). La imagen estereotipada del pimp no corresponde, pues, a la realidad de nuestro trabajo" (ver en http://www.chezstella.org/docs/QueridoCliente.pdf).

4 Salvo en los algunos países donde la prostitución está regulada -Bolivia, Uruguay, Países Bajos, Alemania, Suiza, Austria, Grecia y Turquía-, el proxenetismo es generalmente considerado un delito, sobre todo desde que la Asamblea General de Naciones Unidas firmó el "Convenio para la represión de la trata de personas y de la explotación de la prostitución ajena”, en 1949. En Argentina está tipificado en el Código penal como proxenetismo "promover, facilitar y explotar económicamente la prostitución de una persona, más allá del consentimiento de esta”, acciones que constituyen lo que primero se llamó "delitos contra la honestidad" para luego denominarse "delitos contra la integridad sexual” (Artículos 125 bis y 127).

5 A principios del siglo XX, cuando la "trata de blancas" era una preocupación en los países de Europa central y América, se produjeron y circularon historias sobre jóvenes e inocentes mujeres, secuestradas o engañadas por malvados traficantes para ser obligadas a ejercer la prostitución (Doezema, 1999). En estas narrativas hegemónicas se restringió toda experiencia de migración relacionada a la práctica de la "prostitución" a una dimensión coactiva y violenta (Schettini, 2010). Uno de los libros con mayor circulación de este período fue "El camino de Buenos Aires" del periodista Albert Londres donde la ciudad aparece como un "paraíso de rufianes". Los "rufianes" fueron figuras centrales de estas narrativas, caracterizados como villanos, inmorales y no trabajadores, seres indeseables y sin posibilidad de reinserción social. El comisario Julio Alsogaray en su Trilogía de la trata de blancas sostiene que "los signos degenerativos que lo estigmatizan presentan todas las gradaciones de la vileza (...) para la especial contextura psíquica del rufián no queda otro recurso que eliminarlo mediante su deportación” (Alsogaray, [1933] 2013: 21). Casi un siglo después, en el marco de la campaña anti-trata, la figura del "rufián" vuelve a estar en el centro del debate público, esta vez como tratante de mujeres, representado como un individuo portador de intencionalidades precisas, violento, peligroso e inserto en complejas redes criminales (Varela, 2012), es decir, una figura masculina que se aleja del ideal y moralmente degradada. Esta imagen tanto de rufianes, como de proxenetas o tratantes ha sido alimentada por sus retratos en diversas producciones culturales Sólo por nombrar algunas: novelas como "El infierno prometido", "Las polacas", crónicas como "La trilogía de la trata de blancas" y "El camino a Buenos Aires"; exitosas películas como “Taxi driver" o "Leaving Las Vegas", la telenovela "Vidas Robadas", y las películas argentinas -financiadas por instituciones gubernamentales o no gubernamentales y utilizadas en proyectos educativos escolares - "La Mosca en la ceniza", "La Guayaba” y "Fantasmas de la ruta" (Martynowskyj, 2017).

6 En Argentina, Cecilia Varela (2013), a partir del análisis de sentencias en causas por "trata de mujeres” ha observado que casi la mitad de las procesadas son mujeres, y que más que organizaciones criminales de largo alcance, funcionan redes de ilegalidad de bajo alcance territorial, estructuradas por el parentesco y la división sexual de tareas. Estas características nos permiten tener una visión más matizada de cómo se organiza el mercado sexual en el plano local, donde "la figura estereotipada (y masculinizada) del proxeneta no permite dar cuenta de la variedad de roles y posiciones que permiten la reproducción cotidiana de las personas que ofertan sexo comercial" (Varela, 2016, p. 17). Otrxs investigadorxs (Blanchette y da Silva, 2017) en otros contextos también han señalado la preeminencia de esta modalidad llamada 
“proxenetismo de emprendedor" (O’Connell Davidson, 1998) en la que las propias mujeres que hacen o hicieron comercio sexual son quienes comienzan a fungir como intermediarias o gestoras - muchas veces como forma de organizar su retiro del mercado, dada la imposibilidad de una jubilación-.

7 Utilizamos alternativamente clientes o varones que pagan por sexo, según el aspecto a enfatizar, el primero es el término nativo que circula en el mercado sexual y la segunda es la categoría analítica que proponemos.

8 Proyecto de Investigación Científica y Tecnológica (PICT), Fondo para la Investigación Científica y Tecnológica (FONCyT), "Género y sexualidad en la mirada de varones que pagan por sexo", Argentina.

9 Asimismo, nos referimos a mujeres cis cuando hablamos de escorts pues estas son las más mencionadas por los varones (las "travestis" ocupan una sección aparteen el foro).

10 Si bien fue posible notar algunas variaciones contextuales en relación a las ciudades, estas no son relevantes para el objetivo de este artículo.

11 La denominación 840 proviene de la jerga policial; sería el número del artículo que penaba el proxenetismo.

12 Así se denomina en el ambiente a los departamentos donde una o más mujeres ofrecen servicios sexuales, en general con algún tipo de arreglo económico con un/a tercero/a. Suelen publicitarse por diversas vías (a veces con folletería en la vía pública, y más comúnmente con anuncios encubiertos en la prensa o en páginas web). No siempre están directamente abiertos al público, sino que en muchos casos hace falta concertar una cita telefónicamente o tener alguna referencia para contactarse.

13 Mathieu (2001), por ejemplo, ha planteado las formas de complicidad surgidas entre proxenetas y prostitutas cuando se organizaron las famosas revueltas de la iglesia de St. Nizier.

14 Como hemos señalado en trabajos anteriores, la capacidad para ejercer violencia física parece una potestad de los fiolos. Como contrapartida se reproduce la imagen de las mujeres que hacen comercio sexual como desvalidas y/o necesitadas de protección, una percepción que reproduce los estereotipos que contribuyen a la jerarquización inter-género.

15 En Argentina, se llama "ñoqui" a una persona que cobra sin trabajar, ya sea porque no asiste a su empleo, o porque asiste pero sólo simula trabajar.

16 De acuerdo con Paoli (en Smith y Christou, 2009), este es el motivo por el que La Cosa Nostra italiana no se dedicó inicialmente al proxenetismo, por considerarla una actividad poco honorable.

17 En el lunfardo argentino se llama despectivamente "ortiba" a todo aquel que se opone a la consecución de los deseos de otra persona. A su vez, "otribarse" es definido como: "ponerse en posición de policía, de futuro delator, de cortar un festejo o una actividad que para el otro es buena".

18 Si bien la noción de capital erótico es más compleja -y susceptible de ser criticada (ver Green, 2013)-, en el comercio sexual, tanto como en otros mercados relacionales, hay una relación inversamente proporcional entre capital erótico y edad.

19 Ligado al "cafiolo" y supuestamente también derivado del turco kaftan (Blanchette y Da Silva, 2017).

20 Adicionalmente Blanchette y Da Silva (2017) señalan que este uso, muchas veces llevado a cabo por actores externos al mercado sexual y que buscan impedir cualquier forma de comercio sexual, sirve para encubrir a quienes son más violentos con las trabajadoras (por ejemplo, las fuerzas policiales). 